\title{
Influence of Cold Atmospheric Plasma on Acinetobacter baumannii
}

\author{
Reyam Radi Atta \\ Halah Al Haideri \\ Hamid H Murbat \\ Received 31/10/2018, Accepted 7/1/2019, Published 17/3/2019 \\ This work is licensed under a Creative Commons Attribution 4.0 International License.
}

\begin{abstract}
:
A. baumannii is an aerobic gram negative coccobacilli, it is considered multidrug resistance pathogen (MDR) and causes several infections that are difficult to treat. This study is aims to employ physical methods in sterilization and inactivation of $A$. baumannii, as an alternative way to reduce the using of drugs and antibiotics.

Cold Atmospheric Plasma was generated by one electrode at 20KV, 4 power supply and distance between electrode and sample was fixed on 1mm. A. baumannii (ATCC 19704 and HHR1) were exposed to Dielectric Barrier Discharge type of Cold Atmospheric Plasma (DBD-CAP) for several periods of time (15, 30,45 , and $60 \mathrm{sec}$.) . After sterilization test, several methods were done to analyze the effect of DBD-CAP on bacterial morphology, proteins and DNA. Change in morphology was assessed by cover slid method. Damaged DNA was investigated by PCR technique, and DNA sequencing. The impact of DBD-CAP on the entity of proteins was detected by SDS-PAGE. The observed inactivation of bacterial colony on agar plates has been quantified by measuring the inactivation diameter.

The important conclusion that HHR1 more resistance to DBD-CAP than ATCC 17904 because it is more virulence than standard strain; thus, the growth of both strains is largely affected by plasma and this influence is increased by increasing the time of exposure, also the plasma affects the DNA especially on standard strain as it is explained in sequencing result, so it causes more deletion in DNA sequence. In addition, plasma also has been showed to damage proteins and morphology thus, the bacterial cells transform from cocco-bacillus to bacillus.
\end{abstract}

Key words: Acinetobacter baumannii ATCC17901, Cold Atmospheric Plasma, Dielectric barrier discharge, $H H R I$

\section{Introduction:}

Acinetobacter baumannii is an aerobic, nonfermented Gram-negative coccobacilli, it is grown well on solid media with smooth grayish white colonies. It is identified as one of the main multidrug resistance (MDR) organisms, and it has been considered as a very important pathogen that causes several hospital and community infections, such as ventilator and community acquired pneumonia, meningitis, wound and trauma infections, and septicemia $(1,2)$. It is ubiquitous in nature and commonly associated with aquatic environments, such as water surface, and soil (3). It is found on the skin and it can be isolated in large numbers from the secretions of respiratory and oropharynx of infected person (4). Plasma in physics is the fourth state of matter as ionized gas, is the most matter of universe.

\footnotetext{
1,2 Department of Biology, College of Science for Women, University of Baghdad, Baghdad, Iraq.

${ }^{3}$ Department of Physics, College of Science for Women,

University of Baghdad, Baghdad, Iraq.

*Corresponding author: reyam.radi@yahoo.com
}

It is composed of positive and negative charged ions, electrons and neutral compounds (atoms, molecules), in additional it is composed of radicals and UV-radiation (5). Plasma is divided into two types: thermal and cold atmospheric plasma (CAP). Thermal plasma contains heavy particles and electrons at the same temperature, and the other type called Cold Atmospheric Plasma (CAP) has heavy particles at lower temperature than electrons, less than $40^{\circ} \mathrm{C}$, always be at room temperature. Nowadays, there is an rise attention and work out on cold plasma processes, thus there are numerous means to manufacture the CAP like Dielectric Barrier Discharge (DBD), plasma needle, and plasma pencil, Atmospheric Pressure Plasma Jet (APPJ) (6). Moreover, Cold Atmospheric Plasma has been employed in several sides like, polymerization (7), sterilization/inactivation of microorganisms, this is more essential part since it is participate in keeping life for human beings. It has been depended on either physical or chemical process that destroys or reduces microorganisms, or 
both $(8,9)$ and CAP has been proposed as a therapeutic method to treat cancer (10). In this study the dielectric barrier discharge (DBD) was used, it is well known as one of the plasma sources capable of working with diverse gasses at high pressures (higher than atmospheric pressure) (11). This study aims to employ Cold Atmospheric Plasma (CAP) in treatment of A. baumannii infections to reduce the using of drugs and antibiotics. In addition, the study focuses on the effect of CAP on OmpA gene of $A$. baumannii.

\section{Materials and Methods: \\ Bacterial Sample Preparation}

Two types of $A$. baumannii were used; standard strain A. baumannii ATCC17904 was purchased from (ATCC, USA), and A. baumannii HHR1(Accession number: MH6B5112.1) which was previously isolated from patient attending in Al-Kindi Teaching Hospital. The patient was suffering from urinary tract infection (UTI) and identified by Vitek and 16S rRNA (Accession number: MH6B5112.1). Both types of A. baumannii were routinely cultured on MacConkey agar and nutrient agar, and then incubated at $37^{\circ} \mathrm{C}$ for $24 \mathrm{hrs}$. For liquid cultures, the strains were inoculated in Mueller Hinton (MH) broth and incubated aerobically at $37^{\circ} \mathrm{C}$ for $24 \mathrm{hrs}$ with gentle agitation at $180 \mathrm{rpm}$.The growth cultures of $A$. baumannii was monitored and adjusted till $\mathrm{OD}_{600}$ 0.5-0.6. A $100 \mu \mathrm{l}$ of each culture was spread off on nutrient agar plate, and the plates were left to dry before being incubated at $37^{\circ} \mathrm{C}$ for $24 \mathrm{hrs}$.

\section{DBD Treatment \\ Plasma System}

The DBD system used in this study has been designed and made locally by Dr. Murbat H H/ College of Science for Women/University of BaghdadDr. Hamid H. Murbat (University of Baghdad, College of Science for Women, Department of Physics) Fig.1. It is composed of one electrode with $50 \mathrm{~mm}$ in diameter and made of copper rod surrounding by Teflon for sequestered. Quartz sheet with one millimeter thickness was used as a dielectric substantial between two electrodes. The electrode was linked to high voltage convertor that its output voltages can vary between (1-20 KV). The applied voltage was fixed at (20 $\mathrm{KV}$ ) in our experiment. Samples were placed on the stage and the distance between the electrode and samples was kept as $1 \mathrm{~mm}$. Finally, the plasma region diameter is $2.2 \mathrm{~cm}$.

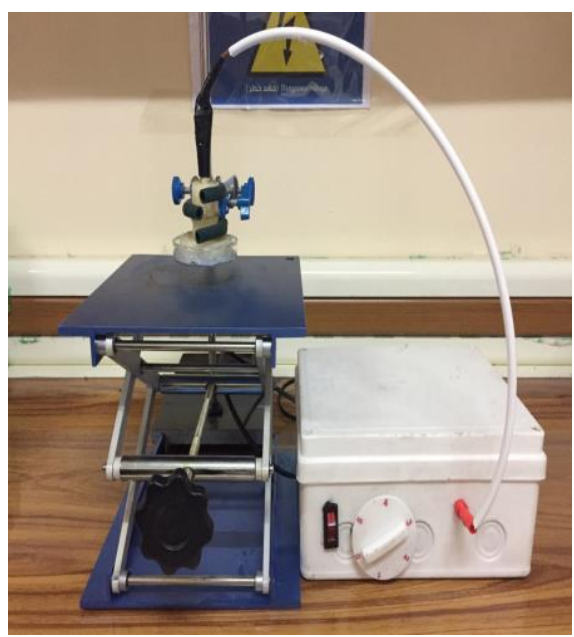

Figure 1. Locally design DBD plasma generator used in this study.

Sterilization tests were employed for both strains, by adding $100 \mu 1$ of overnight incubation suspension and poured on agar surface and left to dry at room temperature for $30 \mathrm{~min}$. After that, sterilization is done by exposing bacteria to DBDCAP for 15, 30, 45, and $60 \mathrm{sec}$. The experiment was conducted in open air under atmospheric pressure and at $14^{\circ} \mathrm{C}$, and one sample was left without exposure to plasma as a control. After treatment was completed, the plates were incubated at $37^{\circ} \mathrm{C}$ for $24 \mathrm{hrs}$ and the inactivation diameter was measured $(12,13)$.

\section{Outer Membrane Extraction}

The OMP fraction of A. baumannii cultures were prepared following a procedure described previously by Jyothisri, et al., (14) with some modifications. Each of overnight liquid culture was treated with DBD-CAP of both A. baumannii strains, ATCC 17904 and HHR1, and control was pelleted by centrifugation at $4000 \mathrm{rpm}$ for $10 \mathrm{~min}$. The pellet was resuspended in $10 \mathrm{mM}$ of Tris- $\mathrm{HCl}$ $\mathrm{pH} 8$, and then re-centrifuged as above. After final wash step, the pellet was sonicated for $15 \mathrm{sec}$ pulses $\mathrm{x} 6$ at frequency amplitude of 16 microns using a soniprep 150 ultrasonic disintegrator (SANYO) and pelleted by centrifugation at $10.000 \mathrm{rpm}$ for $10 \mathrm{~min}$. To separate the outer membrane from the whole cells, the supernatant was discarded and the pellet was resuspended in Triton X-100 with gentle mixing for $30 \mathrm{~min}$ at $4^{\circ} \mathrm{C}$. The pellets were obtained by centrifugation at $4000 \mathrm{rpm}$ for $10 \mathrm{~min}$ and the outer membrane fraction was stored at $-20^{\circ} \mathrm{C}$ until use.

\section{Periplasmic Fraction by Osmotic Shock Method}

Both strains of $A$. baumannii, treated and untreated with DBD-CAP, were aerobically grown in $100 \mathrm{ml} \mathrm{MH}$ broth at $37^{\circ} \mathrm{C}$ for $24 \mathrm{hrs}$ with gentle shaking. The cells were harvested by centrifugation 
at $8000 \mathrm{xg}$ for $10 \mathrm{~min}$ at $4^{\circ} \mathrm{C}$ and resuspended in 10 $\mathrm{ml} \mathrm{STE} \mathrm{buffer}(20 \%[\mathrm{w} / \mathrm{v}]$ sucrose, $30 \mathrm{mM}$ Tris$\mathrm{HCl} \mathrm{pH} \mathrm{8,} \mathrm{and} \mathrm{1mM} \mathrm{EDTA)} \mathrm{and} \mathrm{then} \mathrm{incubated}$ with gentle shaking for $30 \mathrm{~min}$ at room temperature. The cells were pelleted by centrifugation $(10,000$ $\mathrm{xg}, 10 \mathrm{~min}$ at $25^{\circ} \mathrm{C}$ ), resuspended in $5 \mathrm{ml}$ ice-cold $10 \mathrm{mM}$ Tris- $\mathrm{HCl} \mathrm{pH}$ 8.0, followed by incubation with gentle shaking $\left(20 \mathrm{rpm}, 2 \mathrm{hr}, 4^{\circ} \mathrm{C}\right)$. Finally, the periplasm fraction was obtained by centrifugation $\left(15,000 \mathrm{xg}, 25 \mathrm{~min}\right.$, and $\left.4^{\circ} \mathrm{C}\right)$ and then either stored at $-20^{\circ} \mathrm{C}$, or mixed with $1 \mathrm{X}$ SDS loading dye and electrophoresed on $12 \%$ SDS-PAGE. The preparation of periplasm is performed by isolation procedure for Pseudomonas aeruginosa (15).

\section{Preparation of Cytoplasmic Fraction}

Overnight cultures of A. baumannii strains (treated and untreated with DBD-CAP) were harvested by centrifugation ( $4000 \mathrm{xg}, 10 \mathrm{~min})$, and decant the supernatant. The pellet is resuspended in $2 \mathrm{ml}$ Tris-HcL pH 8 and mixed gently. The solution is sonicated four times, $15 \mathrm{sec}$. for each one. Finally, centrifugation for 10-15 min was done, and the supernatant was either used or stored at $20^{\circ} \mathrm{C}(16)$.

\section{Protein Manipulation \\ Determination of Protein Concentration}

The concentration of soluble proteins, cytoplasm and periplasm proteins, was determined by using Bio-Rad Protein Assay (17). Protein samples were diluted in $800 \mu \mathrm{l}$ of $4 \mathrm{x}$ Bio-Rad reagent and $200 \mu \mathrm{l} \mathrm{dH}_{2} \mathrm{O}$ to reach the final concentration of $1 \mathrm{x}$. Then, the solution was transferred to $1 \mathrm{ml}$ volume cuvette, and 1-20 $\mu \mathrm{l}$ protein solution was added. Thereafter, the mixture was measured at $\mathrm{OD}_{595} \mathrm{~nm}$ using spectrophotometer (Optima, Japan). The protein concentration ( $\mathrm{mg} \mathrm{ml}^{-}$ $\left.{ }^{1}\right)$ was calculated using the formula: Protein concentration $\left(\mathrm{mg} \mathrm{ml}^{-2}\right)=\left(\mathrm{OD}_{595} \times 15\right) /$ volume of protein $(\mu 1)$.

On the other hand, the concentration of insoluble protein (whole cells and membrane proteins) was determined using Lowry assay (18). Protein standard and samples were diluted in several solutions with ddH2O. Solution A $(2 \%$ [w/v] sodium carbonate and $0.1 \mathrm{~N}$ sodium hydroxide) was mixed with solution B $(4 \%$ [w/v] cupric sulphate pentahydrate and $1 \%$ potassium sodium tartraate) to give solution C. Solution $\mathrm{C}$ was added to each tube with protein standard and samples, and incubated at room temperature for 10 min. Folin reagent (solution D) was added to the tubes to final concentration $1 \mathrm{X}$ and incubated at RT for $30 \mathrm{~min}$. The absorbance was measured at 600 $\mathrm{nm}$ in comparison to blank that does not contain protein samples.

\section{SDS-PAGE (One Dimensional SDS- polyacrylamide Gel Electrophoresis)}

SDS-polyacrylamide electrophoresis was done using Bio-Rad system (19). $12 \%$ resolving gel and $4 \%$ stacking gel were prepared from the same component while resolving and stacking gel with Tris- $\mathrm{HCl} \mathrm{pH} 8.8$ and Tris- $\mathrm{HCl} \mathrm{pH} 6.8$ respectively. Protein samples were prepared by mixing with $4 \mathrm{x}$ SDS loading dye and boiled at $95^{\circ} \mathrm{C}$ for $5 \mathrm{~min}$. After gel setting, the comb was removed from stacking gel, then gel was located in a gel tank with $1 \mathrm{x}$ SDS running buffer $(25 \mathrm{mM}$ Tris, $250 \mathrm{mM}$ Glycine, and $0.1 \%$ [w/v] SDS). The samples were then loaded into the gel with PageRuler ${ }^{\mathrm{TM}}$ Plus Unstained Rec. Protein Ladder (Promega). The gel was electrophoresed at a constant $100 \mathrm{v}$ until the dye reached to the bottom or as desired.

Gel was stained with Coomassie blue $(50 \%$ [v/v] methanol, $10 \%$ [v/v] glacial acetic acid, $0.1 \%$ [w/v] Coomassie brilliant blue R (Sigma-Aldrich) and destained in $(50 \%[\mathrm{v} / \mathrm{v}]$ methanol, $10 \%[\mathrm{v} / \mathrm{v}]$ glacial acetic acid) twice or until the proteins became visible.

\section{Morphology Assay}

The cell morphology of A. baumannii strains (ATCC 17904 \& HHR1) and control were determined under light microscope after staining with gram stain (20).

\section{Genomic DNA Extraction and Polymerase Chain Reaction}

Plasma-treated culture for both strains (standard and HHR1) was centrifuged at 2,500 $\mathrm{xg}$ for $15 \mathrm{~min}$ to obtain the pellet. Genomic DNA was then extracted from the pellet by Wizard Genomic DNA Purification Kit (Promega, Madison, WI, USA).The OmpA gene of A. baumannii for both strains was amplified by PCR using the OmpA primers (Forward primer 5'ATGAAATTGAGTCGTATTGC-3', and Reverse primer 5' $\quad$-TTATTGAGCTGCTGCAG-3').The concentration of each primer was adjusted to $10 \mu \mathrm{M}$ using $\mathrm{dH}_{2} \mathrm{O}$. All reactions were performed with GoTaq Green Master mix (Promega). 50 $\mu$ l PCR reaction was used that contained $25 \mu$ l Mastermix, $5 \mu \mathrm{l}$ of each primer, $2.5 \mu \mathrm{l}$ of genomic DNA as a template, and sterilized water to make final volume up to $50 \mu 1$. Amplification program was conducted as follows: initial denaturation step at $95^{\circ} \mathrm{C}$ for $1 \mathrm{~min}$, followed by 25 cycles at $95^{\circ} \mathrm{C} 30 \mathrm{sec}$ for denaturation, annealing at $56^{\circ} \mathrm{C} 30 \mathrm{sec}$, extension at $72^{\circ} \mathrm{C} 30 \mathrm{sec}$, final extension at $72^{\circ} \mathrm{C}$ for $1 \mathrm{~min}$, and holding at $4^{\circ} \mathrm{C}$. The PCR product was examined on agarose gel to confirm that there is a specific product with the desired size. The PCR product was sequenced using automated DNA sequencer 
(AB13730XL) (Macrogen Company in Korea). The results were analyzed by BLAST website on NCBI (21).

\section{Statistical Analysis}

Statistical analyses were performed using GraphPad Prism v.7. In addition, quantitative assay was done by using linear regression and statistical significance was defined as $\mathrm{P} \leq 0.05$.

\section{Results and Discussion:}

\section{Effect of Cold Plasma on Bacterial Growth}

Cultures of $A$. baumannii strains were exposed to DBD-CAP at fixed discharge voltage 20 $\mathrm{kv}, 4$ power supply and fixed distant $1 \mathrm{~mm}$. Sterilization test for both strains (Standard and HHR1) showed the inactivation diameter is increased by increasing the exposure time Fig. 2. In A. baumannii ATCC17904, the inactivation gap was increased from $2.5 \mathrm{~cm}$ to $4 \mathrm{~cm}$ after $60 \mathrm{sec}$, while the HHR1isolated was less inhibited after $60 \mathrm{sec}$ exposure time (Table 1).
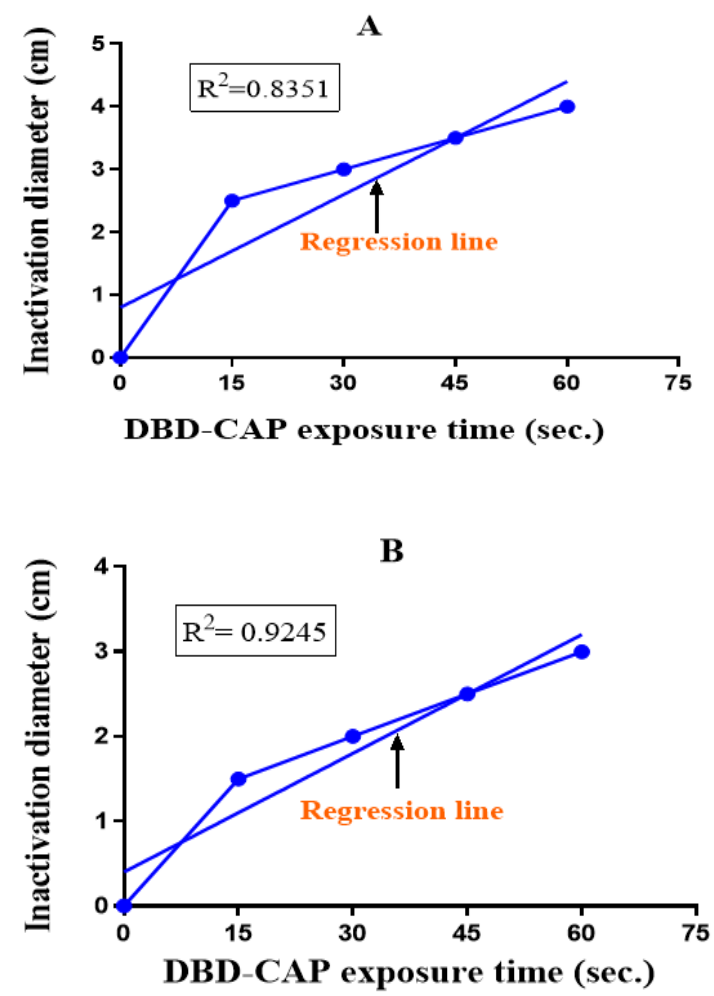

Figure 2. Plasma exposure timeline for $A$. baumannii (A) ATCC 17904, (B) HHR1. A. baumannii cultures were exposed to DBD-CAP at different time intervals. The regression line was plotted in according to the exposure time.
Table 1: Inactivation diameters of $A$. baumannii ATCC 17904 and HHR1 exposure to DBD-CAP.

\begin{tabular}{ccc}
\hline $\begin{array}{l}\text { DBD-CAP } \\
\text { exposure } \\
\text { time (sec.) }\end{array}$ & $\begin{array}{l}\text { Inactivation } \\
\text { diameter of } \\
\mathbf{1 7 9 0 4}(\mathbf{c m})\end{array}$ & $\begin{array}{l}\text { Inactivation } \\
\text { diameter } \\
\text { HHR1 (cm) }\end{array}$ \\
\hline 0 & 0 & 0 \\
15 & 2.5 & 1.5 \\
30 & 3 & 2 \\
45 & 3.5 & 2.5 \\
60 & 4 & 3 \\
P value & $0.0300^{*}$ & $0.0090^{*}$ \\
& $*(\mathbf{P}<\mathbf{0 . 0 5})$ & \\
\hline
\end{tabular}

These results proved that sterilization by DBD-CAP is efficient, it can be notified very well (22). The neutral and charge particles of plasma cause damage to cell, air plasma for example is a perfect source of reactive oxygen-based and nitrogen-based species (ROS and RNS) such as O, $\mathrm{O}_{2}, \mathrm{O}_{3}, \mathrm{OH}, \mathrm{NO}, \mathrm{NO} 2$, etc. and by chemical interaction with macromolecules such as membrane lipids, proteins and nucleic acids. These species cause rupture to cell membrane, followed by bacterial death $(23,24)$. Furthermore, Fig. 3 clearly shows that the bacteria were dead after exposure to DBD-CAP $20 \mathrm{kv}$ for $60 \mathrm{sec}$. Thus, because of the charged particles (ions \& electrons) of plasma play an important role in rending the outer membrane of bacterial cells when they accumulate on the cell surface and forming of electrostatic tensions which lead to cause the disturbance of the cell membrane. Moreover, plasma may catalyze the oxidation and peroxidation processes within the cell and in the external environment which would lead to inactivation of bacterial metabolism $(24,25)$. 

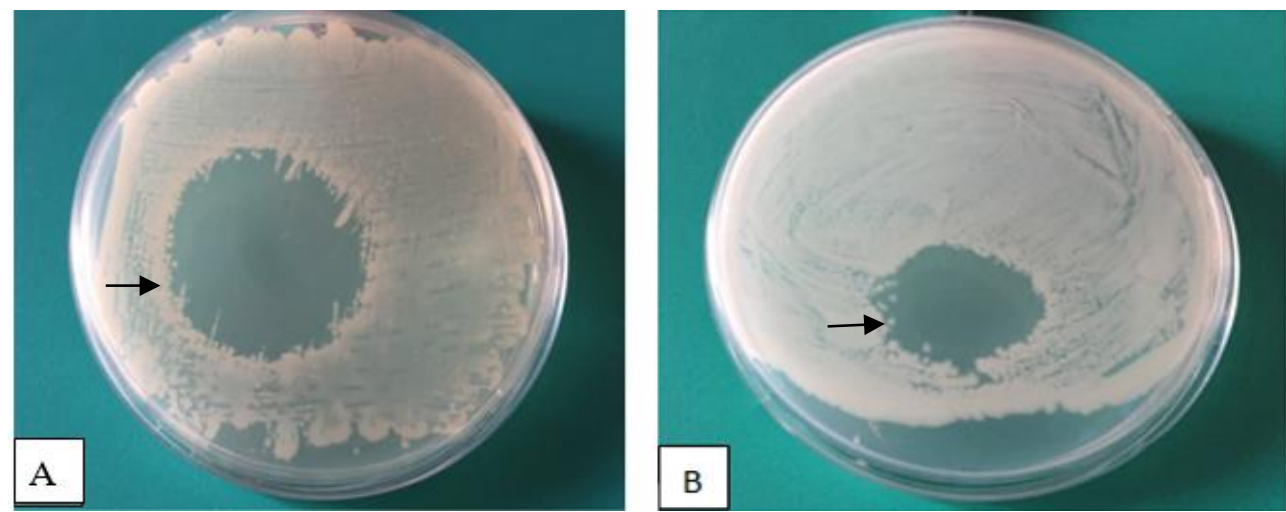

Figure 3. Effect of cold plasma on A. baumannii strains. Nutrient agar plates inoculated with $100 \mu \mathrm{l}$ of A. baumannii strains and exposed to DBD-CAP for 60 sec. (A) ATCC 17904 (B) HHR1. The inhibited region is referred by black arrows.

\section{Effect of Plasma on General Morphology}

Light microscope images of standard strain treated by DBD-CAP and untreated cells stained with Gram stain are shown in Fig. 4. Smooth coccobacilus bacterial cells were observed in samples that untreated with plasma, following cells that exposed to plasma, as it seems below that the morphology of cells undergo some conformational changes after plasma treatment, and plasma may be deleterious to the cell wall structure.
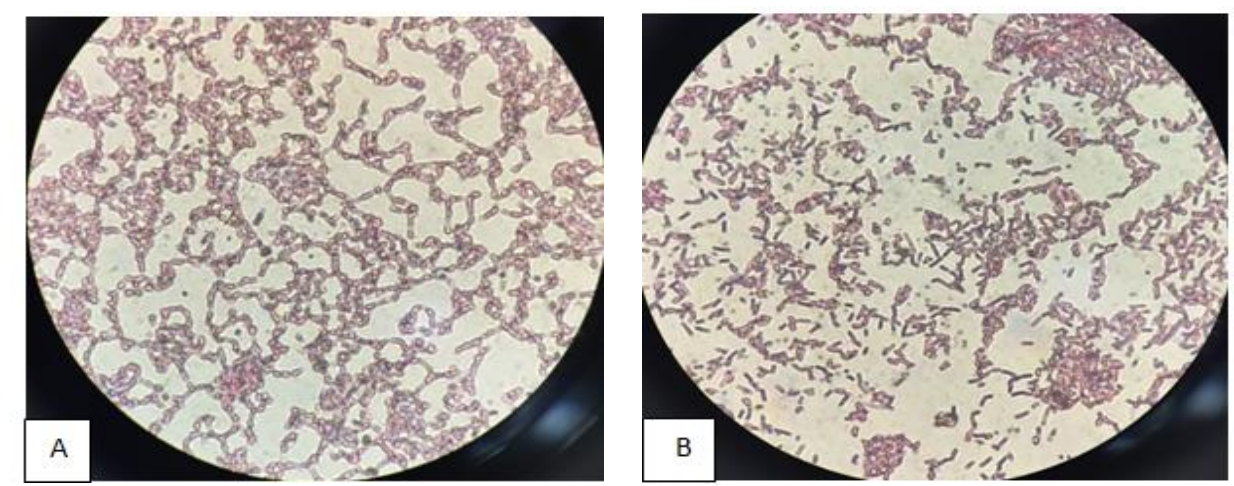

Figure 4. A. baumannii ATCC 17904 treated by sublethal dose of DBD-CAP under Light microscope with 40X magnification (A) before treatment (B) after treatment. In all cases, bacteria were stained with gram stain.

In addition, DBD-CAP has a potential effect on HHR1 morphology Fig. 5, there are obvious changes in the morphology after DBD-CAP treatment. The LM images for both strains with sub lethal dose demonstrated that the cells elongated with no clear appearance of cell lysis. It was reported that cell lysis may not be the essential mechanism for bacterial inactivation, or it may be performed at lethal dose of plasma $(26,27)$, and also plasma did not affect the acceptance of cells to the gram stain.
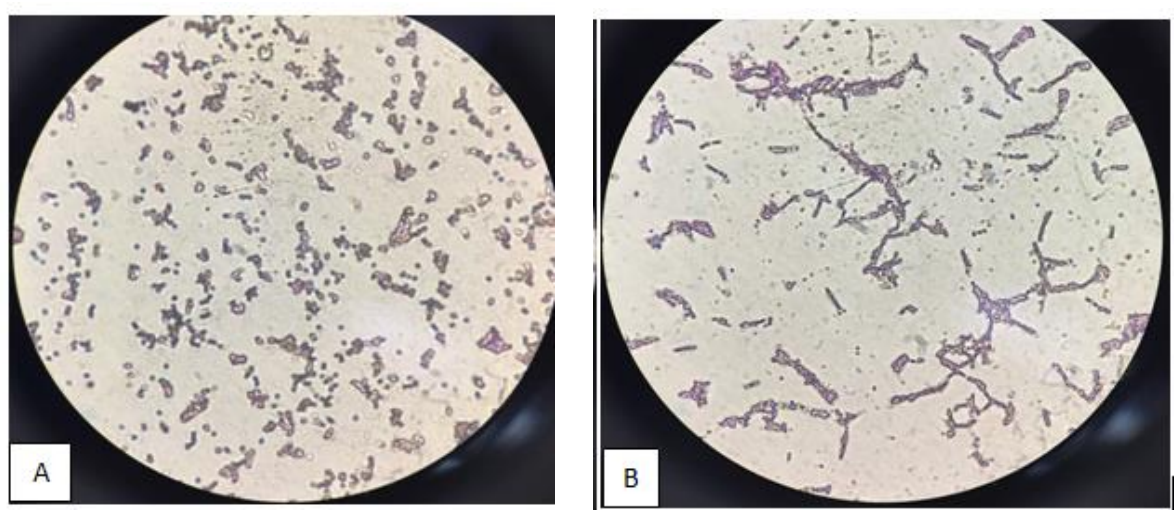

Figure 5. A. baumannii HHR1 treated by sublethal dose of DBD-CAP under Light microscope with 40X magnification (A) before treatment (B) after treatment. In both cases, bacteria were stained with Gram stain. 


\section{Effect of Plasma on DNA}

The DNA was extracted from both treated and untreated cells of strains, then $O m p A$ gene was amplified by PCR as described previously. The PCR products of DBD-CAP treated and untreated strains were electrophoresed on agarose gel electrophoresis Fig. 6A, thus the PCR product for all samples appeared as a clear band with corresponding size of 1071 bp, Fig. 6 B.

A

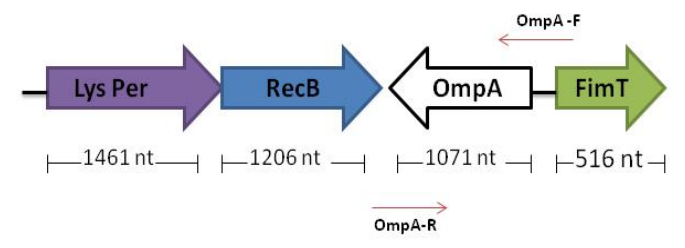

B

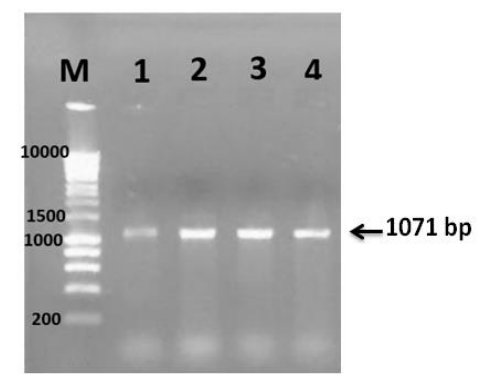

Figure 6. Detection of OmpA gene in $A$. baumannii. (A) OmpA gene organization map. The location of $O m p A$ was determined and specific primers were designed. The gene of interest was PCR amplified using OmpA-F / $O m p A$-R primer pairs. (B) The PCR product was loaded on $1 \%$ agarose gel. The products size was 1071 bp (black arrow). lane M: HypperLadder ${ }^{\mathrm{TM}}$ I Molecular Marker (Biolone), lane 2: amplified OmpA gene in ATCC 17904 normal, lane 3: ATCC 17904 treated with plasma, lane 4: amplified $O m p A$ gene in HHR1 isolate normal, lane 5: HHR1 treated with plasma.
Furthermore, sequencing of $O m p A$ gene was performed to investigate the genetic variation of A. baumannii ATCC 17904 and HHR1 resulted from exposure to DBD-CAP treatment in comparison with the control. In Fig. 7, the sequence alignment of OmpA gene of both strains with the relative strain of A. baumannii ATCC 19606 (accession number: AY485227.1) shows a relative variation in DNA sequences among untreated strain A. baumannii ATCC 1790, treated strain A. baumannii HHR1 DBD-CAP and untreated strain A. baumannii HHR1. Whereas treated strain A. baumannii ATCC 17904 with DBD-CAP exhibited a huge variations with all aligned sequences. The $A$. baumannii ATCC 17904 strain displayed more sequence variation than $A$. baumannii HHR1 isolate. The sequence implies more deletion in DNA sequence in comparison with control and $A$. baumannii HHR1 isolate. The result suggests that the DNA damage is dependent on the type of bacteria (28). In addition, several studies reported that one of most inactivation mechanism of plasma is the UV radiation, which caused damage to DNA by inducing the formation of thymine dimmers (29). Moreover, the reactive species generated by plasma, hydrogen peroxide, single oxygen and ozone have strong oxidative effect that cause damage to DNA, as well as peroxynitrite that formed due to the reaction of nitric oxide and superoxide $(21,30)$. 
ATCC17904 N. ATTACTAAAAACTACGACAGCAAAATCAAGCCGTACGTATTATTAGGTGC

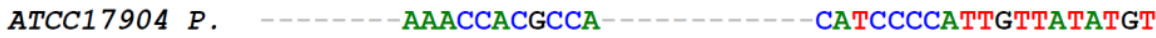
HHR1 $N$. HHR1 $P$. ATTACTAAAAACTACGACAGCAAAATCAAGCCGTACGTATTATTAGGTGC ATTACTAAAAACTACGACAGCAAAATCAAGCCGTACGTATTATTAGGTGC

ATCC19606

360

370

380

390

400

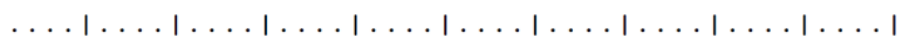
TGGTCACTATAAATACGACTTTGATGGCGTAAACCGTGGTACACGTGGTA ATCC17904 N. TGGTCACTATAAATACGACTTTGATGGCGTAAACCGTGGTACACGTGGTA ATCC17904 P. HHR1 $N$. CGG GTCGTTCACC----TGCGGATCGTC HHR1 $P$. TGGTCACTATAAATATGACTTTGATGGCGTAAATCGTGGTACACGTGGTA TGGTCACTATAAATACGACTTTGATGGCGTAAACCGTGGTACACGTGGTA

ATCC19606

410

420

430

440

450

$\ldots|\ldots| \ldots|\ldots| \ldots|\ldots| \ldots|\ldots| \ldots|\ldots| \ldots \mid$ CTTCTGAAGAAGGTACTTTAGGTAACGCTGGTGTTGGTGCTTTCTGGCGC ATCC17904 N. ACTCAGAAGAAGGTACTTTAGGTAACGCTGGTGTTGGTGCTTTCTGGCGC ATCC17904 P. HHR1 $N$. HHR1 $P$. CCTCAGA TCAGCAACCAACGTTTCGTTGGCGACAGGCGC CTTCTGAAGAAGGTACTTTAGGTAACGCTGGTGTTGGTGCTTTCTGGCGC ACTCAGAAGAAGGTACTTTAGGTAACGCTGGTGTTGGTGCTTTCTGGCGC

ATCC19606 $\begin{array}{lllll}460 & 470 \quad 480 & 490 & 500\end{array}$ TT---AAACGACGCTTTATCTCTTCGTACTGAAGCTCGTGCTACTTATAA ATCC17904 N. TT---AAACGATGCTTTATCTCTTCGTACTGAAGCTCGTGCTACTTATAA ATCC17904 P. ATGCGGAATGACAATCTATTCCGGCGT---------CGCCACTGGCAC HHR1 $N$. HHR1 $P$.

TT---AAACGACGCTTTATCTCTTCGTACTGAAGCTCGTGCTACTTATAA TT---AAACGATGCTTTATCTCTTCGTACTGAAGCTCGTGCTACTTATAA

ATCC19606 $\begin{array}{lrrr}510 & 520 & 530 & 540\end{array}$ $\ldots|\ldots| \ldots|\ldots| \ldots|\ldots| \ldots|\ldots| \ldots|\ldots| \ldots|\ldots|$ ATCC17904 N. TGCTGATGAAGAGTTCTGGAACTATACAGCTCTTGCTGGCTTAAACGTAG ATCC17904 P. HHR1 $N$. HHR1 $P$.

TGCTGATGAAGAGTTCTGGAACTATACAGCTCTTGCTGGCTTAAACGTAG --CTCATGGCGGGTTAC--------_CGGCACTTTTTCGCTTAA TGCTGATGAAGAGTTCTGGAACTATACAGCTCTTGCTGGCTTAAACGTAG TGCTGATGAAGAGTTCTGGAACTATACAGCTCTTGCTGGCTTAAACGTAG

ATCC19606 560 570 580 590 600 $\ldots . \ldots . \ldots|\ldots| \ldots|\ldots| \ldots|\ldots| \ldots|\ldots| \ldots|\ldots|$ ATCC17904 N. ATCC17904 P. HHR1 $N$. HHR1 $P$.

TTCTTGGTGGTCACTTGAAGCCTGCTGCTCCTGTAGTAGAAGTTGCTCCA TTCTTGGTGGTCACTTGAAGCCTGCTGCTCCTGTAGTAGAAGTTGCTCCA TAGCTTGC

TTCTTGGTGGTCACTTGAAGCCTGCTGCTCCTGTAGTAGAAGTTGCTCCA TTCTTGGTGGTCACTTGAAGCCTGCTGCTCCTGTAGTAGAAGTTGCTCCA

610

620

630

640

650

ATCC19606 $\ldots \ldots|\ldots| \ldots|\ldots| \ldots|\ldots| \ldots|\ldots| \ldots|\ldots| \ldots|\ldots|$ ATCC17904 N. ATCC17904 P. HHR1 $N$.

GTTGAACCAACTCCAGTTGCTCCACAACCACAAGAGTTAACTGAAGACC' GTTGAACCAACTCCAGTTGCTCCACAACCACAAGAGTTAACTGAAGACCT CTACCGTTGC CAGGAAATAAC----GACC GTTGAACCAACTCCAGTTGCTCCACAACCACAAGAGTTAACTGAAGACCT 
HHR1 $P$.

ATCC19606

ATCC17904 N.

ATCC17904 P.

HHR1 $N$.

HHR1 $P$.

ATCC19606

ATCC17904 N. ATCC17904 P.

HHR $1 \mathrm{~N}$.

HHR1 $P$.

ATCC19606

ATCC17904 N.

ATCC17904 P.

HHR1 $N$.

HHR1 $P$.

ATCC19606

ATCC17904 N.

ATCC17904 P.

HHR1 $N$.

HHR1 $P$.

ATCC19606

ATCC17904 N. ATCC17904 P. HHR1 $N$.

HHR1 $P$.

ATCC19606

ATCC17904 N. ATCC17904 P.

HHR1 $N$.

HHR1 $P$.
GTTGAACCAACTCCAGTTGCTCCACAACCACAAGAGTTAACTGAAGACCT

660
$\ldots .|\ldots| \ldots|\ldots| \ldots|\ldots| \ldots|\ldots| \ldots|\ldots| \ldots|\ldots| \ldots \mid \ldots 10$ TAACATGGAACTTCGTGTGTTCTTTGATACTAACAAATCAAACATCAAAG TAACATGGAACTTCGTGTGTTCTTTGATACTAACAAATCAAACATCAAAG

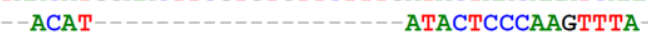

TAACATGGAACTTCGTGTGTTCTTTGATACTAACAAATCAAACATCAAAG TAACATGGAACTTCGTGTGTTCTTTGATACTAACAAATCAAACATCAAAG

$\begin{array}{ccccc}710 & 720 & 730 & 740 & 750\end{array}$ ACCAATACAAGCCAGAAATTGCTAAAGTTGCTGAAAAATTATCTGAATAC ACCAATACAAGCCAGAAATTGCTAAAGTTGCTGAAAAATTATCTGAATAC

ACCAATACAAGCCAGAAATCGCTAAAGTTGCTGAAAAATTATCTGAATAC ACCAATACAAGCCAGAAATTGCTAAAGTTGCTGAAAAATTATCTGAATAC

$\begin{array}{lllll}760 & 770 & 780 & 790 & 800\end{array}$ ССTAACGCTACTGCACGTATCGAAGGTCACACAGATAACACTGGTCCACG CCTAACGCTACTGCACGTATCGAAGGTCACACAGATAACACTGGTCCACG C CCTAACGCTACTGCACGTATCGAAGGTCACACAGATAACACTGGTCCACG CCTAACGCTACTGCACGTATCGAAGGTCACACAGATAACACTGGTCCACG

810
$\ldots .|\ldots| \ldots|\ldots| \ldots|\ldots| \ldots|\ldots| \ldots|\ldots| \ldots|\ldots| \ldots|\ldots|$ TAAGTTGAACGAACGTTTATCTTTAGCTCGTGCTAACTCTGTTAAATCAG TAAGTTGAACGAACGTTTATCTTTAGCTCGTGCTAACTCTGTTAAATCAG

TAAGTTGAACGAACGTTTATCTTTAGCTCGTGCTAACTCTGTTAAATCAG TAAGTTGAACGAACGTTTATCTTTAGCTCGTGCTAACTCTGTTAAATCAG

$\begin{array}{rrrr}860 & 870 & 880 & 890\end{array}$ CTCTTGTAAACGAATACAACGTTGATGC-TTCTCGTTTGTCTACTCAAGG CTCTTGTAAACGAATACAACGTTGACGCTTTCTCGTTTGTCTACTCAAGG -TTCACTCA

CTCTTGTAAACGAATACAACGTTGACGC-TTCTCGTTTGTCTACTCAAGG CTCTTGTAAACGAATACAACGTTGACGC-TTCTCGTTTGTCTACTCAAGG

$\begin{array}{lllll}910 & 920 & 930 & 940 & 950\end{array}$ TTTCGCTT-GGGATCAACCGATTGCTGACAACAAAACT-AAAGAAGGTCG TTTCGCTTGGGGATCAACCGATTGGTGACAACAAAACTAAAAAAAGGTCG - -TCGC---CGGATT--CCGACTGCCAAGCACAAAACT-TTTCGCTT-GGGATCAACCGATTGCTGACAACAAAACT-AAAGAAGGTCG TTTCGCTT-GGGATCAACCGATTGCTGACAACAAAACT-AAAGAAGGTCG

960
970

$\begin{array}{lllll}1010 & 1020 & 1030 & 1040 & 1050\end{array}$ $\ldots|\ldots| \ldots|\ldots| \ldots|\ldots| \ldots|\ldots| \ldots|\ldots| \ldots|\ldots|$ -GTAGTAGTTCAACCTGGTCAAGAAG-CGGCAGCTCCTGCAGCAGCTCAA GGTATAAGTTCAACCTGGGTCAGAAGCCGGCAGCTCCTGCGTAGACTTCC -GTGGTTTCTCAATAAATTGCACAAT

-GTAGTAGTTCAACCTGGTCAAGAAG-CGGCA----CTCTGGCGCCCCTC -GTAGTAGTTCAACCTGGTCAAGAAG-CGGCAGCTCTGC--GCAGCCCTC

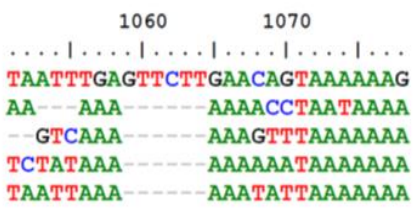

Figure 7. Sequence alignment of $O m p A$ gene for $A$. baumannii strains ATCC 17904 strain and $A$. baumannii HHR1 isolates. Both strain and isolate were exposed to DBD-CAP and their sequenced were aligned with the corresponding strain ATCC 19606 (Sequence ID: AY485227.1) from NCBI. $\mathrm{N}$; is referred to normal (control or untreated), P; represents the plasma treatment. The sequence alignment was done by MEGA program, and the graphic view was displayed by Bioedit service. 
Does Cold Plasma Disrupt the Bacterial Plasma Membrane and Cell Wall?

To unequivocally determine the ability of cold plasma to damage the cell wall and penetrate to the cytoplasm, A. baumannii DBD-CAP treated and untreated cells were fractionated into cytoplasm $(\mathrm{Cyt})$, periplasm (PM), and outer membrane (OM), and all fractions were mixed with $1 \mathrm{X}$ SDS loading dye and resolved on $12 \%$ SDS-PAGE before being visualized by UV. Figure 7 showed that the DBDCAP is fairly damage the cell wall and penetrate to the cytoplasm and target the DNA, where $A$. baumannii ATCC 17904 is more sensitive to DBDCAP than A. baumannii HHR1. As shown in Fig. 8 $\mathrm{A}$, there is no change in $\mathrm{OM}, \mathrm{PM}$ and cytoplasm of standard strain. This perhaps proves that cold plasma affects proteins only at lethal dose instead of sub-lethal does. Fig. 8B did not show any damage in the cytoplasm or in somehow PM and OM, however, PM is slightly smear and unclear in comparison to the control, and thus might due to the technical trouble shoot in SDS-PAGE and for CAP in particular. The effect of cold plasma on the cell wall integrity was stated in previous study which reported that a partial or complete destruction of plasma membrane architecture occurred when E.coli cells are treated with cold plasma, and triggers all the intracellular material out of the cells and ultimately death (31).

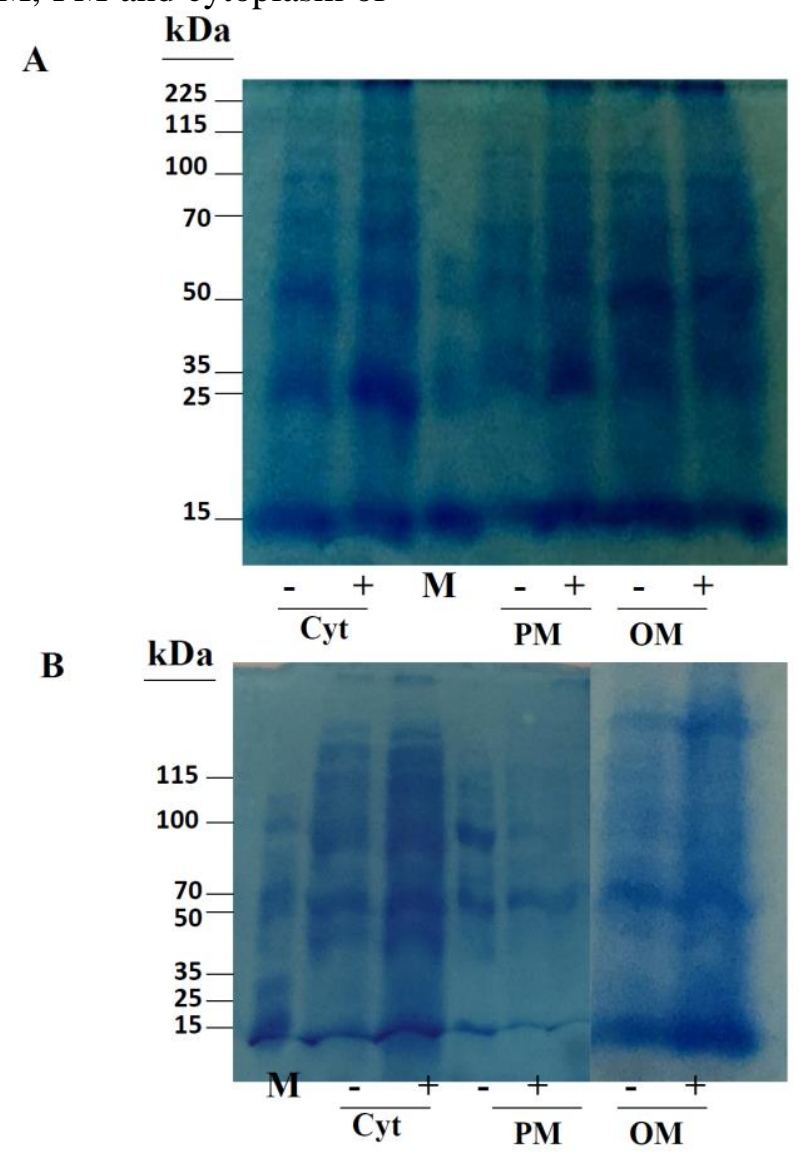

Figure 8. One dimensional SDS-PAGE of $A$. baumannii fractions. Overnight cultures of $A$. baumannii were fractionated into periplasm by osmotic shock procedure, outer membrane by Triton $\mathrm{X}-100$ and cytoplasm. All fractions for both treated and untreated cells were mixed with 1X SDS loading dye and subjected to $12 \%$ SDS-PAGE. A: Coomassie blue staining of $A$. baumannii ATCC 17904 fractions; B; SDS-PAGE for A. baumannii HHR1isolate. In all cases: Lane M: is the PageRuler ${ }^{\mathrm{TM}}$ Plus Unstained Rec. Protein Ladder (Promega). The sign - refers to the untreated cells with cold plasma; the sign + is represents the cells treated with CAP; Cyt: is the cytoplasm, PM is periplasm and OM is the outer membrane. $35 \mu \mathrm{g}$ of proteins were loaded into each well.

\section{Conclusion:}

The growth of both strains (ATCC 17904 and HHR1) of A. baumannii is affected by exposure to DBD-CAP for several time intervals and the inactivation diameter is increased via increasing the time of exposure. Moreover, A. baumannii HHR1 isolate was more resistant to the effect of DBDCAP than A. baumannii ATCC 17904; the inactivation diameter for the later was greater than that for the A. baumannii HHR1. 


\section{Conflicts of Interest: None.}

\section{References:}

1. Martín-Aspas A, Guerrero-Sánchez FM, GarcíaColchero F, Rodríguez-Roca S, Girón-González JA. Differential characteristics of Acinetobacter baumannii colonization and infection: Risk factors, clinical picture, and mortality. Infect Drug Resist. 2018;11:861-72.

2. Harding CM, Hennon SW, Feldman MF. Uncovering the mechanisms of Acinetobacter baumannii virulence. Nat Rev Microbiol [Internet]. 2018 Feb;16(2):91-102. Available from: http://dx.doi.org/10.1038/nrmicro.2017.148

3. Higgins PG, Hrenovic J, Seifert H, Dekic S. Characterization of Acinetobacter baumannii from water and sludge line of secondary wastewater treatment plant. Water Res. 2018 Sep;140:261-7.

4. Correa A, del Campo R, Escandón-Vargas K, Perenguez $M$, Rodríguez-Baños $M$, HernándezGómez C, et al. Distinct Genetic Diversity of Carbapenem-Resistant Acinetobacter baumannii from Colombian Hospitals. Microb Drug Resist [Internet]. 2018 Jan 1;24(1):48-54. Available from: http://www.liebertpub.com/doi/10.1089/mdr.2016.01 90

5. Ayan H, Fridman G, Gutsol AF, Vasilets VN, Fridman A, Friedman G. Nanosecond-pulsed uniform dielectric-barrier discharge. IEEE Trans Plasma Sci. 2008 Apr;36(2 PART 2):504-8.

6. Hoffmann C, Berganza C, Zhang J. Cold Atmospheric Plasma: Methods of production and application in dentistry and oncology. Med Gas Res. 2013 Dec;3(1).

7. Bitar R, Cools P, De Geyter N, Morent R. Acrylic acid plasma polymerization for biomedical use. Appl Surf Sci [Internet]. 2018 Apr;448:168-85. Available from: https://doi.org/10.1016/j.apsusc.2018.04.129

8. Chiang MH, Wu JY, Li YH, Wu JS, Chen SH, Chang CL. Inactivation of $\mathrm{E}$. coli and $\mathrm{B}$. subtilis by a parallel-plate dielectric barrier discharge jet. Surf Coatings Technol [Internet]. 2010 Aug 15;204(2122):3729-37. Available from: http://dx.doi.org/10.1016/j.surfcoat.2010.04.057

9. Feng $X$, Liu H, Shen Z, Wang T. Removal of Microbial Contamination from Surface by Plasma. InIOP Conference Series: Earth and Environmental Science 2018.

10. Chen Z, Lin L, Zheng Q, Sherman JH, Canady J, Trink B, et al. Micro-sized cold atmospheric plasma source for brain and breast cancer treatment. Arxiv.org [Internet]. 2018 Apr;1-20. Available from: http://arxiv.org/abs/1804.08421

11. Mustafa MF, Fu X, Liu Y, Abbas Y, Wang H, Lu W. Volatile organic compounds (VOCs) removal in nonthermal plasma double dielectric barrier discharge reactor. J Hazard Mater [Internet]. 2018 Apr;347(January):317-24. Available from: https://doi.org/10.1016/j.jhazmat.2018.01.021.

12. Khalaf TH, Al-fahdawi ARMG, Hussein MU. The role of atmospheric non-thermal plasma in the bacteria inactivation.IJP. 2015;13(26):92-100.
13. Ayan H, Fridman G, Gutsol AF, Vasilets VN, Fridman A, Friedman G. Nanosecond-pulsed uniform dielectric-barrier discharge. IEEE Trans Plasma Sci. 2008 Apr;36(2 PART 2):504-8.

14. Jyothisri K, Deepak V, Rajeswari MR. Purification and characterization of a major $40 \mathrm{kDa}$ outer membrane protein of Acinetobacter baumannii. FEBS Lett [Internet]. 1999 Jan;443(1):57-60. Available from: http://www.ncbi.nlm.nih.gov/pubmed/9928952

15. Hamzehpour MM, Pechere J, Plesiat P. OprK and OprM define two genetically distinct multidrug efflux systems in Pseudomonas aeruginosa. These include : OprK and OprM Define Two Genetically Distinct Multidrug Efflux Systems in Pseudomonas aeruginosa. 1995 Nov 1;39(11):2392-6.

16. Horwich AL, Low KB, Fenton WA, Hirshfield IN, Furtak K. Folding in vivo of bacterial cytoplasmic proteins: Role of GroEL. Cell. 1993 Sep 10;74(5):909-17.

17. Bradford MM. A rapid and sensitive method for the quantitation of microgram quantities of protein utilizing the principle of protein-dye binding. Anal Biochem. 1976 May 7;72(1-2):248-54.

18. Markwell MAK, Haas SM, Bieber LL, Tolbert NE. A modification of the Lowry procedure to simplify protein determination in membrane and lipoprotein samples. Anal Biochem. 1978 Jun 15;87(1):206-10.

19. Al-Haideri H. Characterization of novel proteins in the cell envelope of Campylobacter jejuni.The University of Sheffield. 2015.

20. Smith AC, Hussey MA. Gram Stain protocol. Am Soc Microbial [Internet]. 2005 Sep 30:(1-9). Available from: http://www.austincc.edu/microbugz/gram_stain.php.

21. Lu H, Patil S, Keener KM, Cullen PJ, Bourke P. Bacterial inactivation by high-voltage atmospheric cold plasma: Influence of process parameters and effects on cell leakage and DNA. J Appl Microbiol. 2014 Apr;116(4):784-94.

22. Joaquin JC, Kwan C, Abramzon N, Vandervoort K, Brelles-Mariño G. Is gas-discharge plasma a new solution to the old problem of biofilm inactivation? Microbiology. 2009 Mar 1;155(3):724-32.

23. Abbas IK, Hussein MU, Muthanna H, Murbat HH. The Effect of the Non-Thermal Plasma Needle on Pseudomonas Aeruginosa Bacteria. Iraqi J Sci [Internet]. 2017;58(3A):1214-9. Available from: http://www.ijs.scbaghdad.edu.iq/issues/Vol58/No3A/ Vol58Y2017No3APP1214-1219.pdf

24. Khalaf TH, Hussein MU, Al-fahdawi ARMG. Effect of Atmospheric Non-Thermal Plasma on Adhesion Process of Pseudomonas Spp Bacteria. 2015 IJP;18(3):74-9.

25. Pandit S, Vrss M, Helgadóttir SH, Westerlund F, Mijakovic I. Combination of Cold Atmospheric Plasma and Vitamin C Effectively Disrupts Bacterial Biofilms. Clin Microbiol. 2017;6(3):10-3.

26. Duske K, Jablonowski L, Koban I, Matthes R, Holtfreter B, Sckell A, et al. Cold atmospheric plasma in combination with mechanical treatment improves osteoblast growth on biofilm covered titanium discs. Biomaterials. 2015 Jun 1;52(1):327-34.

27. Ziuzina D, Patil S, Cullen PJ, Keener KM, Bourke P. 
Atmospheric cold plasma inactivation of Escherichia coli in liquid media inside a sealed package. J Appl Microbiol. 2013 Sep 1;114(3):778-87.

28. Cooper M, Fridman G, Fridman A, Joshi SG. Biological responses of Bacillus stratosphericus to Floating Electrode-Dielectric Barrier Discharge Plasma Treatment. J Appl Microbiol. 2010 Des;109(6):2039-48.

29. Fernández A, Thompson A. The inactivation of Salmonella by cold atmospheric plasma treatment. Food Res Int [Internet]. 2012 Mar 1;45(2):678-84. Available from: http://dx.doi.org/10.1016/j.foodres.2011.04.009

30. Guo L, Xu R, Gou L, Liu Z, Zhao Y, Liu D, et al.
Mechanism of Virus Inactivation by Cold Atmospheric-Pressure Plasma and Plasma-Activated Water. Appl Environ Microbiol [Internet]. 2018 Jun 18;84(17). Available from: http://aem.asm.org/lookup/doi/10.1128/AEM.007261829.

31.Kobzev EN, Kireev GV, Rakitskii YA, Martovetskaya II, Chugunov VA, Kholodenko VP, Khramov MV, Akishev YS, Trushkin NI, Grushin ME. Effect of cold plasma on the E. coli cell wall and plasma membrane. App Biotech Microbiol [Internet]. 2013 Mar 1;49(2):164-70. $10.1134 / \mathrm{S} 0003683813020063$.

\section{دراسة تأثير البلازما الباردة على بكتريا الراكدة البومانية}

حامد مربط
هاله الحيدري

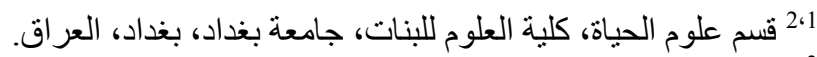

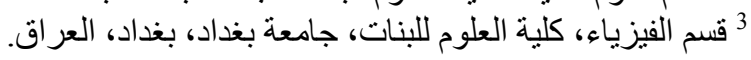

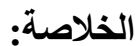

تهدف هذه الرسالة الى توظيف طر ائق فيزيائية في معالجة الراكدة البومانية وذلك لغرض التقليل من استخدام الادوية والعقاقير.

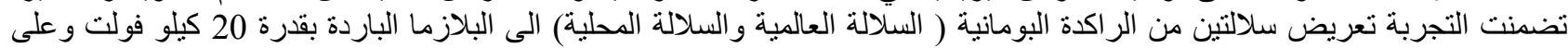

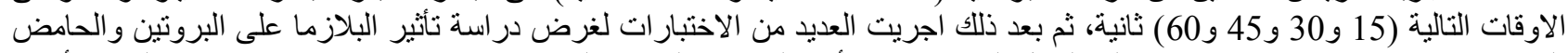

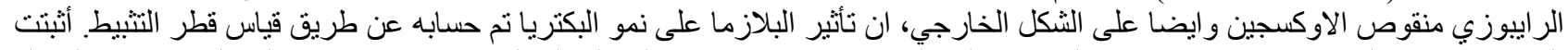

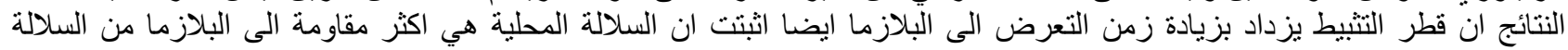

الكلمات المفتاحية: الر اكدة البومانبة السلالة العالمية، البلازماالباردة، حاجز ثنائي القطب، السلالة المحلية. . 